\title{
UN DECRETO MAS DE NUEVA PLANTA
}

\author{
POR \\ JOSE LUIS BERMEJO CABRERO \\ Universidad Nacional de Educación a Distancia
}

No es la nueva planta impuesta por Felipe $V$, cuya secuela ha llegado a nuestros días, $\tan$ bien conocida como fuera de esperar. Sin duda será un tema a trabajar en los próximos años, aunque sólo sea por la actualidad que haya cobrado en nuestros días. Frente a los trabajos publicados, algunos de muy certera factura, existe una amplia documentación, aún no bien explotada. Y muchas cuestiones a plantear: que la época y el ambiente histórico, al ser mejor conocidos, van a permitir, a no dudarlo, trazar nuevas conexiones y poder preguntar más a fondo.

Hasta ahora los decretos de nueva planta conocidos, desde el ángulo hispánico, eran los relativos a los territorios peninsulares de la Corona de Aragón (Valencia y Aragón primero; nuevo decreto para Aragón más tarde, y por fin Cataluña, ya en 1716). Más los decretos de las islas, Mallorca y, a fin de siglo, Menorca. Nos referimos a los textos más importantes; que hubo necesidad de normas complementarias, a veces con el propio nombre de decreto. Pero los territorios a los que se aplicó la nueva planta no eran más que los enumerados. Así es como se ha expuesto la cuestión desde los manuales académicos a las más ceñidas monografías ${ }^{1}$. Pues bien, hoy podemos referirnos a un nuevo decreto, concedido al reino de Cerdeña, a fin de establecer en el reino la nueva planta borbónica.

Para la nueva organización de la isla se va a utilizar, como en otros casos, un decreto, que lleva fecha de 24 de noviembre de 1717 , y dos años después se dictará una real cédula con referencia expresa al mencionado decreto y amplio desarrollo de la nueva planta en forma articulada, a base de treinta y dos capítulos ${ }^{2}$. Conviene reparar en el tipo de disposiciones que se adoptan.

1 En el manual más reciente escrito hasta la fecha de Historia del Derecho, F. Tomás Valiente dedica al tema de la nueva planta un amplio tratamiento, Manual de Historia del Derecho español (Madrid, 1979), 379-475. En notas siguientes iremos viendo otros trabajos.

${ }^{2}$ Real cédula de 16 de febrero de 1719 . Se encuentra la real cédula en AHN, Osuna, leg. 3.117, núm. 4. Puede verse en nuestro apéndice documental con referencia a los pasajes paralelos - con mayor o menor coincidencia- del decreto catalán.

Para el decreto de 16 de enero de 1716 seguimos el texto de la Novísima Recopilación, V, 9, 1 (ed. Códigos españoles, 8 [Madrid, 1850], 53-56). 
En los demás casos de nueva planta se utiliza, como es sabido, el tipo de disposición conocida con el nombre de decreto. Es natural que sea así, al ser los decretos las disposiciones más características dimanantes de la soberanía real, que van directamente dirigidas a una determinada institución u organismo. Se establece así una inmediata relación entre el soberano que dicta la norma y el órgano que ha de aplicarla ${ }^{3}$. Puede ocurrir que luego semejante disposición, para darla una más amplia ejecutividad y aún mayor difusión, se incluya dentro del marco formal de una real cédula. Muchos decretos, de sencilla configuración inicial, aparecen luego revestidos de todo el aparato de la real cédula, cuya solemnidad se advierte ya en el propio dictado o intitulación con el rey de que se trate exhibiendo la titularidad de sus diversos dominios ${ }^{4}$. Pues bien, si en los otros territorios buena parte de la organización - y la más importante desde luego- se traza por real decreto, ahora en Cerdeña, al lado del decreto, tendremos una real cédula, en la que descansa prácticamente el esquema de la organización toda. Es más, lo que conservamos -a falta de una más ceñida investigación - es la real cédula; el decreto como tal lo conocemos sólo por la mención con que se inicia la real cédula, al decir: «Sabed que por quanto en consecuencia de tener yo mandado por decreto de veinte y quatro de noviembre del año passado de mil setecientos diez y siete, señalado de mi real mano, que en esa isla y Reyno haya una audiencia»s. Hasta aquí la referencia escueta. Viene luego el desarrollo de la real cédula en los referidos treinta y dos artículos.

Ahora bien, el nuevo procedimiento suponía algunos cambios en los usos ordinarios. La real cédula por regla general era como la vía ordinaria para dirigirse a las autoridades territoriales y a los súbditos. Sólo que la tramitación de la real cédula — de no emplearse los modos nuevos de la vía reservada, a cargo de los secretarios del despacho-, solía encauzarse a través del Consejo de Castilla e iba dirigida, según cláusulas que llamaríamos de estilo, a una serie de autoridades y organismos del reino, junto a los súbditos o vasallos en general ${ }^{6}$. En la real cédula de Cerdeña no sucede ni lo uno ni lo otro. Es una

${ }^{3}$ A. García Gallo ha señalado agudamente el significado y presencia en el xvIII de los decretos. Manual de Historia del Derecho español (Madrid, 1973), 214. Véase también, F. Tomás Valiente, Manual, 377-378.

$4 \mathrm{Y}$ es que, como ya probara el profesor García Gallo, para distinguir correctamente los distintos tipos de disposiciones hay que emplear diversos criterios: por la forma, contenido y fuerza o vigor de la disposición. De ahí que una misma disposición pueda ser considera. da o denominada como tal de diversas formas. A. García Gallo, La Ley como fuente en Indias, en AHDE, 21 (1951), 607-740, y ahora en sus Estudios de Historia del Derecbo indiano (Madrid, 1972), 169-285, y su Manual de Historia del Derecho, 208-216.

${ }^{5}$ Véase sobre regesta del decreto la nota 8.

- Se produce en las reales cédulas un curioso proceso de transformación a lo largo del tiempo, recargando sus aspectos formales.

En el siglo xviII lo normal es que la real cédula vaya a nombre del Rey y del Consejo de Castilla «Real Cédula de S. M. y Señores del Consejo» y lleve una amplia intitulación o dictado: «Don Felipe, don Fernando o don Carlos, por la gracia de Dios, rey de Castilla, de León, de Aragón, de las dos Sicilias, de Jerusalén, de Navarra, de Granada, de Toledo», etcétera. Se emplean más sencillas formalidades en caso de ser tramitada la real cédula por vía reservada. Ejemplo: Real cédula de S. M. sobre la educación, trato y ocupaciones de los esclavos. Madrid, 31 de mayo de 1789. En AHN, Reales Cédulas, núm. 898. La intitulación 
real cédula en cuanto aparece calificada como tal real cédula en el texto articulado ${ }^{7}$. Lo es también por la consabida intitulación solemne «Don Felipe quinto por la gracia de Dios», con la enumeración de cuantos dominios posee. En cambio, ni aparece la mención al Consejo de Castilla - lo que es natural en un reino de nueva incorporación - ni tampoco la amplia enumeración de destinatarios de la real cédula, sino que su dirección es más modesta y concreta, al estilo de la empleada en los decretos ${ }^{8}$. Todas estas particularidades conviene señalarlas: que pueden significar para Cerdeña, ya que no la concesión de un peculiar modo de organización, al menos un trato especial en el empleo de formalidades.' De ahí la serie de adaptaciones en la tipología de la normativa usual ${ }^{9}$.

Pero la nueva organización no se limitaba en los planteamientos borbónicos a sólo la parte oriental y más rebelde a la dinastía. También se quiso llevar el espíritu reformista, con el bien significativo nombre de nueva planta, a territorios castellanos, en donde había tantas instituciones que no guardaban uniformidad. Se trataría de aplicar unos mismos modelos institucionales a los organismos más altos que venían funcionando a base de privilegios y estilos an-

es así de simple: «El Rey». No va a nombre del Consejo y va dirigida al correspondiente secretario del Despacho, en este caso Porlier.

7 Aunque en la portada no lleve el título de real cédùla, se recoge en el articulado, capítulo 32: «Por esta mi Real Cédula». Y en las cláusulas finales: "Como si fuese esta mi Real Zédula original». Ello no quiere decir que fuera Cerdeña el único territorio en que se dictaran, con motivo de la nueva planta, reales cédulas.

- «A don Gonzalo Chacón, comandante general de mi Reyno de Zerdeña, regente y oydores de mi real audiencia». Tales debieton ser las autoridades existentes a la sazón en la isla. No se utiliza una «dirección» al uso castellano, porque faltan aún las correspondientes figuras a las que dirigirse, alguna de las cuales se van precisamente a establecer ahora -corregidor, justicias-.

Gonzalo Chacón aparece incluido entre los virreyes en la valiosa obra de Josefina Mateu Ibars, Los virreyes de Cerdeña, II (Padua, 1964-68), 236.

En esta obra se citan dos documentos, procedentes del Archivo de Estado de Cáller, que son sin duda los mismos a los que aquí hacemos referencia:

«Madrid 1718, Enero, 11. Nueva formación de la Real Audiencia compuesta de un regente, cuatro ministros, para la Sala de 10 Civil y otros para la Criminal y dos fiscales.

1719, Febrero, 16. Pragmática de Felipe V concediendo la reforma de la Real Audiencia, y de otros tribunales i oficios, así como la supresión de otros, tal es el Tribunal de la Gobernación de Sasser. Ordena el cese de las prohibiciones referentes a los forasteros».

Previamente en el texto de la obra se había indicado: «Felipe V de Borbón por carta de 17 de Febrero de 1719, mandaba observar un decreto de 32 capítulos. Sobre la nueva organización de la Real Audiencia, restablecida por Real Decreto de 24 de Febrero de 1717, con el Consejo de Justicia, Tribunal y Junta Patrimonial, que debía estar compuesto de cuatro fiscales por la Sala Civil y de otros tantos por la Criminal; se suprimían diversos oficios entre ellos el Tribunal de la Gobernación de Sasser y se nombraban corregidores y Regidores en las principales ciudades de la isla para la administración de justicia y para el gobierno político, así como alcaides y regidores en todos los ayuntamientos» (pág. 234).

Con independencia de algún pequeño matiz -decreto o pragmática, por real cédula; alcaide, por alcalde- se está apuntando en tales regestas al mismo tipo de documentación sobre la que basamos nuestro trabajo, aunque - por tratarse de simples resúmenes- sin valorarla, ni ponerla en conexión con los decretos de nueva planta.

${ }^{9}$ Las breves puntualizaciones que sobre las reales cédulas hemos recogido en el texto son de aplicación al siglo XVIIr. En épocas más antiguas - y el tema arranca, como se sabe, de la Baja Edad Media- las formalidades de las reales cédulas son mucho más sencillas y las cláusulas menos estereotipadas. 
tiguos, difíciles de conocer y aủn de manejar para quienes no mantuvieran relación muy directa con los propios organismos. La compleja mecánica de la Monarquía española, que sirviera en algún momento de admiración a los de fuera, se había hecho de tan difícil manejo, que no se veía otra salida que someterla a drásticas medidas de reforma. Y entre los organismos de más necesitada reforma estaban los Consejos, de varia configuración, lento modo de operar y predominio nobiliario, contra los cuales en vano se habían ensayado medidas de urgencia para hacerlos más idóneos y operativos ${ }^{10}$. Profunda reforma en los poderosos Consejos y potenciación de figuras de mayor empuje y eficacia, iba a ser parte importante del programa reformista del equipo borbónico, con Orry en un primer plano ${ }^{11}$.

A los Consejos se les iba a someter a un proceso de transformación concebido en amplios términos, aunque parte de la reforma terminara luego en fracaso. Consejos de inmediata relación con el monarca y amplia configuración, o se quedan marginados y a solas con su honor, mas sin funciones efectivas al no convocarlos siquiera - Consejo de Estado- o se ven reducidos a la casi exclusiva función de administrar justicia - Consejo de guerra-. Y a otros Consejos supremos, cuando no se extinguen, a falta de territorios donde proyectarse - caso del Consejo de Italia- se les somete a drásticas transformaciones, con funciones más compartidas y sometidos a control ${ }^{12}$. Si luego hubo que dar marcha atrás en la reforma, los planes estaban ahí, y fueron en la época calificados de «nueva planta», a la manera de territorios más próximos al Mediterráneo.

Una nueva planta, pues, de altos organismos y tribunales quiso imponerse a un lado y otro de la monarquía, para hacer realidad los ideales uniformistas y centralizadores, como más eficaces y manejables que se creían. Allí donde razones bélicas lo permitieron se habló de medidas frente a súbditos rebeldes o de simple proyección de la soberanía real, que puede hacer cambios e introducir reformas a su manera de pensar; y en aquellos otros territorios fieles, o menos bulliciosos, se invocarían a tales efectos de transformación razones técnicas y de reforma administrativa ${ }^{13}$. Eran nuevos tiempos en los que el rey

10 Numerosos decretos fueron dirigidos, por ejemplo, al Consejo de Estado para regular su proceder y hacer más rápidas y uniformes las consultas emitidas, sin diferenciación de votos.

${ }^{11}$ Diversos datos pueden verse en José Antonio Escudero, Los secretarios de Estado y del Despacho, I (Madrid, 1969), 281-316, y Orígenes del Consejo de ministros, I (Madrid, 1979), 19-60. Con manejo de nuevas fuentes H. Kamen, La Guerra de Sucesión en España 1700-1705 (Barcelona, 1974), 120.127.

12 Sobre la nueva planta de otros Consejos hay abundantes datos en el Archivo Histó. rico Nacional, sección de Estado. En otro momento nos ocuparemos del tema.

Las reformas del Consejo de Castilla han sido estudiadas por la profesora francesa Janine Fayard, La tentative de réforme du conseil de Castille sous le règne de Philippe V (1713-1715), en Mélanges de la Casa de Velázquez, II (1966), 259-281.

${ }_{13}$ El trato más desfavorable fue el dispensado al reino de Valencia que, como se sabe, no recuperaría, al modo de Aragón, parte de su derecho tradiçional. Se ha comentado repetidas veces el decreto de 1707 . El texto fue publicado en Novísima Recopilación, III, 3, 1. F. Tomás Valiente comenta el texto e inserta un amplio fragmento en Los Decretos de nueva planta (Alcira, 1979), y en su Manual de Historia del Derecho español, 371-375. Tomás Valiente ha insistido en la política discriminatoria de Felipe V.

Sobre Valencia entre los trabajos recientes puede verse: M. Peset Reig, Notas sobre la 
quiere gobernar con un equipo bien conjuntado de secretarios de Estado y del despacho, sin necesidad de tanta consulta a Consejos ni de confiar a tan lentos organismos medidas de ejecución ${ }^{14}$. Avalado todo ello en el lado oriental por el modelo castellano de organización que se iba a imponer. Resulta así el programa reformista un tanto consecuente y que supo valerse coyunturalmente de la victoria.

Cerdeña es un buen ejemplo. Si entró en la contienda sucesoria del lado aliado no fue por un acto de rebeldía, como los invocados en la Península, sino al quedar encuadrada la isla en el dominio austríaco. Vino luego la campaña italiana de Alberoni y Cerdeña volvió a ser española, a lo que parece, con una favorable acogida de sus habitantes ${ }^{15}$. No podía hablarse ahora de

abolición de los fueros de Valencia, en Anuario de Historia del Derecho español, 42 (1972), 657-716. Bibliografía en pág. 658.

Para Aragón clara y precisa síntesis en Jesús Lalinde Abadía, Los fueros de Aragón (Zaragoza, 1976), 129-132. Aragón, frente a Mallorca y Cataluña, perdería su derecho penal tradicional. Un planteamiento general de la Guerra de Sucesión en Aragón y Valencia, con interesantes referencias institucionales, en $\mathrm{H}$. Kamen, La Guerra de Sucesión.

${ }_{14}$ Considera Orry que uno de los defectos del sistema polisinodial era el de encomendar -prácticamente sin control- medidas ejecutivas a los Consejos. AHN, Estado, libro 696, fol. 323-324.

P. Voltes Bou, al revisar hace unos años el tema de la nueva planta, insistió en la influencia austríaca - frente a la francesa- de las ideas centralizadoras, tal como se manifiestan en el caso de Olivares; y trató de aminorar la idea de «punición y represalia» que animaba a los Decretos (Felipe $V$ y los fueros de la Corona de Aragón, en REP [1955], 77-120).

${ }_{15}$ En agosto de 1717 España tomaría posesión de Cerdeña. Un trabajo reciente sobre las operaciones militares - partida de la expedición; toma de Caller (Cagliari), Alger, Castillo Aragonés y vuelta de las tropas expedicionarias- es, del lado español, el de Miguel Angel Alonso Aguilera, La conquista y el dominio español en Cerdeña (1717-1720) (Valladolid, 1977).

Sobre la favorable acogida de las tropas españolas puede verse Joaquín Arce, España en Cerdeña. Aportación cultural y testimonios de su influjo (Madrid, 1960), 205-206. Contiene esta obra del ilustre profesor madrileño interesantes síntesis sobre diversos aspectos de la isla. Los aspectos institucionales en páginas 48-54. Una amplia bibliografía histórica en páginas $463-470$. Y un interesante repaso a las actitudes de la historiografía italiana ante el. dominio español (págs. 203-214).

La profesora Josefina Mateu Ibars aporta asimismo otra bibliografía importante en Los virreyes de Cerdeña, I, págs. 18-26. Y es que la bibliografía sobre la isla es muy abundante y especializada, de difícil manejo incluso para los propios historiadores italianos, que pasan de largo en ocasiones sobre la época aquí estudiada. Hay que pensar, además, que durante la dominación española Cerdeña fue uno de tantos territorios hispánicos sometidos a un poderoso influjo de la metrópoli, que se advertirá incluso años después de la pérdida de la isla.

$\mathrm{Ni}$ en historias de difusión como la amplia de Gervasio Montanelli, Storia d'Italia, ni en otras más especializadas, como la dirigida por Atilio Levi, Societá e costume (con un volumen dedicado a L'Italia Nell ottocento), por poner dos ejemplos significativos, se aborda el tema del cambio institucional suscitado por el dominio hispánico.

Ya en el siglo pasado se redactó una importante bibliografía sobre la historia de Cerdeña por un español, Eduardo Toda y Güell, Bibliografía española sobre Cerdeña (Madrid, 1890), que junto a las fichas bibliográficas ofrece en ocasiones referencias a los autores o al contenido de las obras. A esta obra siguieron otras, algunas de las cuales pueden verse en el citado estudio sobre virreyes de la profesora Mateu Ibars.

Del lado español, una reciente visión general de la época en $\mathrm{G}$. Anes, El antiguo régimen, los Borbones, en Historia de España, Alfaguara, IV (Madrid, 1975), 349. Para una 
súbditos rebeldes, ni apelar extemporáneamente a la real soberanía; ni se quiso invocar, por elemental cortesía tal vez, el derecho de conquista, sino tan sólo marcar los derroteros de la nueva planta, tomando como modelo uno de los existentes, que fue, como hemos dicho, el catalán. Una vez que se aplicó en la nueva planta la teoría de los modelos, lo más consecuente en un caso aislado, y como sobrevenido, era no inventarse nuevo modelo, sino aprovechar uno de los más cercanos, con tales o cuales ocasionales retoques de adaptación. Y ello fue lo que se hizo.

Si pasamos ya al contenido de la organización, se hace al modo catalán. Con una docena menos de capítulos, a consecuencia sobre todo de una labor de refundición, la real cédula sarda viene a ser un traslado - con retoques aquí y allá para no confundirla con los usos de la isla- de lo dispuesto por el largo decreto dirigido a la Audiencia de Barcelona con fecha 16 de enero de 1716.

No vamos a entrar en el examen de todos los aspectos de la nueva organización, para no repetir cuanto sabemos sobre el tema catalán, del que existen importantes estudios ${ }^{16}$. Nuestra exposición se ceñirá al marco general y a las peculiaridades más notorias de Cerdeña, ya sea por omisión o por añadimiento, con respecto al caso catalán.

Ante todo la real cédula se limita a desarrollar lo dispuesto en el decreto, por el que se creaba la Audiencia. La real cédula da por supuesta la creación de la Audiencia y su más elemental organización: un regente y unos oidores, a los cuales precisamente va dirigida la real cédula. No sucede como en Cataluña en que creación y desarrollo van unidos.

Comienza la organización con el tema de la presidencia. $\mathrm{Y}$ aquí se da un matiz diferenciador con Cataluña que conviene subrayar; a veces una simple palabra puede tener un profundo significado, cual sucede en este caso. Si en Cataluña presidía la Audiencia «el capitán general o comandante general», ahora en Cerdeña, al lado de las figuras militares - capitán general o comandante- aparece alternativamente una autoridad gubernativa de nombre bien característico, el gobernador, que en la isla había tenido larga tradición. Esto significa que al frente de la Audiencia en los aspectos gubernativos, no tenía por qué estar una figura militar, sino la propia autoridad gubernativa, posibilidad que no se daba en Cataluña, como hemos visto, ni en ningún otro territorio de nueva planta, sometidos a una especie de militarización de sus órganos de gobierno. O dicho de otra forma, que en Cerdeña podían subsistir gobernadores, mientras en los demás reinos orientales la figura paralela de los virreyes se había abolido ${ }^{17}$.

Variantes hay también en cuanto al resto de la composición del Tribunal.

valoración del «prerreformismo borbónico, véase lo que dice ese gran historiador que es A. Domínguez Ortiz, Sociedad y Estado en el siglo XVIII español (Madrid, 1976), 84-103.

${ }_{16}$ Son muy importantes los estudios de J. Mercader Riba, publicados en varios números de la revista «Hispania» y luego vertidos al catalán en su Felipe $V i$ Catalunya (Barcelona, 1968).

${ }_{17}$ Real cédula de Cerdeña, núm. 1 (Cataluña, 1).

Sobre la extinción de los virreyes en Cataluña a consecuencia de la nueva planta puede verse la importante obra de J. Lalinde Abadía, La institución virreinal en Cataluña (Barcelona, 1964), 431-437. 
Cerdeña tendrá el mismo tipo de composición, pero, por decirlo así, en menor cuantía: además del regente, cuatro oidores para la sala de lo civil y cuatro para la de lo criminal; frente a los diez y cinco, que había respectivamente en Cataluña. Y lo mismo sucede con los fiscales - dos en lugar de seis-. Es como una Audiencia_a escala menor. Se mantienen los dos fiscales y el alguacil mayor. Y los salarios de unos y otros aparecen fijados aquí también en cuantía y moneda diferente a la del Principado. No se fija, en cambio - y por el momento-, la sede de la Audiencia.

En cuanto al ulterior despliegue de los oficios y regulación del procedimiento judicial -que como en Cataluña se quiere hacer más rápido y eficaz- hay algunos cambios o añadidos notorios. No tendrán voto los fiscales, pero podrán suplicar e interponer recursos ${ }^{18}$. El rey se reserva el nombramiento de ciertos oficios, y se exige aprobación de la Audiencia en aquellos nombramientos hechos por las «comunidades» de ministros y oficiales de justicia, a fin de averiguar la «calidad, aptitud y circunstancias que concurren en los nombrados» ${ }^{19}$. Se perfila mejor que en Cataluña la visita a las cárceles, en la doble vertiente de visita general y específica para lo criminal ${ }^{20}$; y es importante el añadido sobre las apelaciones desde la Audiencia, antes elevadas al Consejo de Aragón y ahora al de Castilla, en el que fue englobado ${ }^{21}$. Y esto sin contar la diferente ordenación de materias o las variantes de palabras sueltas, que alteran a veces el significado de algún fragmento.

En lo relativo a la organización territorial y local se procede de diferente modo que en Cataluña, aunque en parecida dirección. Tal tipo de organización, en su esfera más alta, descansará en la figura del corregidor auxiliándose sus respectivos tenientes, sin hacer ahora distinción entre tenientes letrados y ordinarios. Pero no se hace, como en Cataluña, enumeración de las ciudades y villas con corregidor y tenientes, junto al distrito en que ejercen su jurisdicción, sino que los nombramientos y la señalización de los distritos se dejará para más adelante, una vez mediara información de las autoridades superiores de la Audiencia. Sólo se indica que habrá corregidores en las ciudades más importantes, sin determinar cuáles sean. En cuanto al número de corregidores sucede lo mismo, con la sola excepción de la ciudad de Cáller (Cagliari), con veinte regidores - Barcelona tendría 24-y Sácer (Sassari) con sólo ocho regidores, número igual al de las otras ciudades catalanas ${ }^{22}$.

En los lugares más pequeños hay una diferencia notable con Cataluña, que mantenía como autoridad tipo la figura tradicional del baile. En Cerdeña se aplicará, sin más, el modelo de organización castellana. Habrá alcaldes, justicias y regidores, cuyo nombramiento —como en Cataluña con el baile- y fijación

${ }^{18}$ Real cédula de Cerdeña, núm. 12.

19 Real cédula de Cerdeña, núm. 14 (Cataluña, 16), y 18 (Cataluña, 24).

${ }^{20}$ Real cédula de Cerdeña, núm. 20 (Cataluña, 26).

${ }^{21}$ Real cédula de Cerdeña, núm. 11.

La incorporación del Consejo de Aragón al de Castilla es un tema necesitado de estudio, para el que no falta documentación. Domínguez Ortiz ha señalado que las atribuciones del Consejo de Aragón «no pasaron al de Castilla; en parte pasaron a los secretarios del Despacho, en parte a las Audiencias», A. Domínguez Ortiz, Sociedad y Estado en el siglo XVIII español, 88.

2 Real cédula de Cerdeña, núm. 24 (Cataluña, 30). 
del número se deja a la Audiencia. De ahí que cuando en los artículos siguientes del decreto catalán se hable de «baile», la real cédula sarda empleará en su lugar el nombre de alcalde ${ }^{23}$.

En cuanto a las puntualizaciones sobre el régimen y actuación de unos y otros oficiales, en lugares más o menos importantes, vienen a ser las mismas, con las oportunas variantes que puedan darse en otros casos.

Y en cuanto a la supresión de oficios, se hace en los mismos términos que en el principado de Cataluña, pasando sus funciones en lo relativo a justicia y gobierno a los corregidores, $\mathrm{y}$ en materias de hacienda y rentas, a los intendentes. En la real cédula se hace expresa mención del tribunal de la gobernación de Sácer, como «suprimido y extinto ${ }^{24}$. Y algo parecido cabe decir de la cláusula por la que se restablece «en todo lo demás» la normativa antigua de Cerdeña, que ahora aparece mencionada con más detalle, pues a las Constituciones se añaden las «pragmáticas y leyes que avia en Zerdeña» ${ }^{25}$. Sólo que aquí tal mantenimiento pudiera tener un significado distinto al de Cataluña, el ser reciente la recuperación del territorio y necesitar en consecuencia una declaración de restablecimiento de las disposiciones antiguas que rigieron en la isla.

Una organización, pues, semejante a la catalana, pero con variantes de interés, que permiten mayor flexibilidad a la hora de adoptar los esquemas a los casos concretos. Si en algunos puntos se traza sólo el esbozo dejando lo demás para un ulterior desarrollo, se debe sin duda a la necesidad de dejar establecida una planta para el gobierno y administración de la isla recién conquistada -administración de justicia, sobre todo-, y no esperar más tiempo a tener precisados todos los datos de la nueva planta.

No hubo tiempo, sin embargo, de que el marco aquí expuesto encontrara aplicación y cumplido desarrollo. Ciertos interrogantes que hoy pudiéramos plantear sobre el alcance de la reforma, se mantendrían sólo en el aire, a la manera de las preguntas hechas sobre lo que pudiera haber sucedido si la historia fuera otra. Pues, en efecto, a poco de esbozarse esta nueva planta, Cerdeña saldría del dominio hispánico para recibir otro tipo de estructuras político-administrativas. Y ello contribuiría sin duda a hacer olvidar que en la isla se dieron, como en otros territorios del Mediterráneo, los esquemas de la nueva planta ${ }^{26}$.

${ }^{23}$ Real cédula de Cerdeña, núm. 29 (Cataluña, 38).

${ }^{4}$ Real cédula de Cerdeña, núm. 29 (Cataluña, 37).

25 Real cédula de Cerdeña, núm. 32 (Cataluña, 42, 43 y 44).

Entre los historiadores del Derecho español, R. Gibert ha prestado particular atención a los dominios hispánicos en Italia. En torno a Cerdeña véase la exposición de su Historia general del Derecho español (Madrid, 1971), 407-415, sobre instituciones, normas y literatura jurídica.

${ }_{26}$ No es extraño por eso que en la bibliografía española de Historia del Derecbo no fuera conocida la nueva planta sarda. Y asimismo cabe decir de los trabajos tocantes a la Historiografía menos especializada. Una reciente visión de síntesis sobre la nueva planta acaba de ofrecer la revista «Historia 16», septiembre (1977).

En cuanto a la edición del texto hemos procurado conservar ciertas particularidades en la utilización de consonantes - así en amplio juego de la letra 2 -, cambiando en ocasiones la puntuación o el manejo de mayúsculas. 


\section{NUEVA PLANTA DE LA REAL AUDIENCIA DEL REYNO DE ZERDEÑA ESTABLECIDA POR SU MAGESTAD, CON DECRETO DE VEINTE Y QUATRO DE NOVIEMBRE DE MIL SETECIENTOS DIEZ Y SIETE}

Don Phelipe quinto por la gracia de Dios rey de Castilla, de León, de Aragón, de las dos Sicilias, de Ierusalen, de Navarra, de Granada, de Toledo, de Valencia, de Galicia, de Sevilla, de Serdeña, de Córdova, de Córsega, de Murcia, de Iaén, de los Algarbes, de Algezira, de Gibraltar, de las Islas de Canaria, de las Indias Orientales, Islas y Tierra firme del mar Océano, Archiduque de Austria, Duque de Borgoña, de Bravante y Milán, Conde de Abspurg, de Flandes, Tirol, Rosellón y Barcelona, Señor de Vizcaya y Molina, etc. Don Gonzalo Chacón y Orellana, Comandante General de mi Reyno de Zerdeña, Regente y Oydores de mi Real Audiencia, que reside en la ciudad de Caller; sabed que por quanto en consequencia de tener yo mandado por Decreto de veinte y quatro de Noviembre del año passado de mil setecientos diez y siete. Señalado de mi Real mano que en essa isla y Reyno haya una Audiencia he resuelto aora que en ella se observe y practique todo lo que se expressa en los treinta y dos Capítulos siguientes.

\section{1 (Cataluña, 1)}

Que el Governador, Capitán General o Comandante de las Armas que huviere en esse Reyno, ha de presidir en la Audiencia y los Despachos después de empezar con el dictado de mi Real persona, han de proseguir en nombre del Gobernador, Capitán General o Comandante, el qual ha de tener solamente voto en las cosas de govierno, y esto hallándose presente en la Audiencia; pero en nominaciones de oficios y cosas graves deverá el Regente avisarle un día antes lo que se ha de tratar en papel firmado de su mano o de palabra por medio del scrivano principal de la Audiencia, y si el negocio pidiere prompta deliberación se avisará con más anticipación.

\section{2 (Cataluña, 2)}

Que la referida Audiencia se a de componer de un Regente, cuatro ministros para la Sala Civil, quatro para la Sala Criminal, y dos fiscales. Y los salarios que han de gozar han de ser el Regente dos mil reales de a ocho, y los demás ministros y fiscales mil cada uno al año. $Y$ assí mismo a de haver en ella un alguazil mayor con quinientos reales de a ocho de Salario, el qual a de assistir a la Sala Criminal, visitas de cárcel y rondas, dando quenta luego que executare alguna prisión; y a de hazer lo que se le encargare por las Salas. 


\section{3 (Cataluña, 4 y 5 )}

Las causas y pleytos en la Audiencia se substanciarán en lengua castellana. $Y$, para que por la mayor satisfación de las partes los incidentes de las referidas causas y su formación se traten con mayor solemnidad y deliberación se harán en las Salas todas las peticiones, presentaciones de instrumentos, autos y sentencias, y lo demás que se ofreciere; y para lo corriente y público se tendrá en la civil audiencia pública lunes, miércoles y viernes de cada semana; pero las peticiones y presentaciones de instrumentos se podrán hazer en otros días ante los scrivanos, y se dará quenta en audiencia pública para que no se passen los términos de las causas, si los huviere señalados.

\section{4 (Cataluña, 6)}

Porque puede la malicia de los litigantes procurar la dilación de los pleytos podrán limitarse o ceñirse los términos de prueva y otros según se jusgare ser justo por la Sala, porque su fin a de ser evitar las calumnias y administrar justicia con la mayor brevedad y satisfación de las partes.

\section{5 (Cataluña, 7)}

Que respeto de que la relación de los pleytos ambaraza mucho a los ministros para el más prompto expediente de las causas, aunque las partes por lo passado tenían la satisfación de verse y relatarse por uno de los que havían de votar, mando que haya para la Sala Civil dos relatores graduados de derecho o licenciados en universidades aprovadas y que hayan practicado quatro años con abogado o sido assessores de algún juez ordinario, los quales hayan de tener el primer haziento en el banco de abogados y hazer la relación a puertas abiertas, presentes las partes, si quieren concurrir y sus abogados oyéndoles en derecho. $Y$ han de entregar sumario o memoriales ajustados, si lo mandare la Sala para que se impriman a costa de las partes, comprobados antes en su presencia, o con su citación, sin otro salario que el que abaxo se les señala, teniéndose entendido que los referidos relatores para lo civil an de ser prácticos y expertos en los negocios de Zerdeña para poder comprehender bien los processos y escripturas antiguas, y los eligirá la Sala Civil con intervención del Governador o Comandante General, si quisiere concurrir. Y como antes se pagava, el derecho de sentencias y provisiones en las causas civiles que se aplicava a los ministros, se a de aplicat aora a los relatores, para que cada uno de ellos tenga sobre estos derechos trescientos y sinquenta reales de a ocho al año de salario. Y se cobrarán los referidos derechos de Sentencias y Provisiones de la misma manera que antes, para que los relatores no reciban cosa alguna de mano de las partes, pero quitado el abuso introducido de llevar derecho de sentencia de cada punto o artículo, que en la causa se controvertía sobre cosas diversas o incidentes, pues no se a de poder llevar más que un derecho de sentencia o provisión, aunque en una causa sean muchos los puntos y pretençiones de las partes. Y quando no bastaren estos derechos para la íntegra satisfación del referido salario de los relatores se les suplitá lo que faltare de los efectos de mi Real Hazienda. 


\section{6 (Cataluña, 7)}

A de haver dos relatores para la Sala Criminal con las mismas calidades, circunstancias y salarios que se les pagarán de los mismos derechos y de la misma manera que se previene para los de la Sala Civil. Y la elección destos dos relatores se ha de hazer por la Sala Criminal assistiendo el Regente y Comandante General si quisiere concurrir.

\section{7 (Cataluña, 8)}

Que el fiscal civil assista a su Sala Civil y el Criminal en su Sala Criminal, pero sin voto en las causas uno y otro, $y$ en caso de vacante ausencia o justo impedimento del uno, substituirá el otro en su lugar; y uno y otro de dichos fiscales tendrá su agente fiscal con salario de dosientas y ochenta libras de vellón de Zerdeña cada uno al año.

\section{8 (Cataluña, 9)}

Que en la Sala Civil aya dos scribanos de Cámara para lo civil. Y uno de ellos a de ser el principal y que despache todas las cosas de govierno, y lo demás que la Audiencia le ordenare. Y éste tendrá a su cargo el cuydado del Sello, como también del Archivo, del qual el ministro más moderno a de tener llave de lo que pareciere a la Audiencia deve estar más guardado.

\section{9 (Cataluña, 13)}

Que los abogados y procuradores serán admitidos por la Audiencia y sin esta circunstancia no podrán patrocinar causas.

\section{0 (Cataluña, 14)}

Que los ministros de la Sala Civil han de assistir a ella tres oras por la mañana todos los días que no fueren feriados, y los lunes y jueves por la tarde juntándose con los de la Sala Criminal para tratar cosas de govierno. Y concluido lo de govierno, si sobrare tiempo, se passarán las dos Salas cada una en la suya para votar y decidir los pleytos. Y el Regente assistirá en la Sala Civil y también por las tardes o en la.Sala Criminal, y votará en las causas en que assistiere a la relación.

\section{1 (Cataluña, 3 y 12)}

Que las suplicaciones en una y otra Sala Civil y Criminal se interpondrán en los casos permitidos a la misma Sala donde se a dado la sentencia o declaración. $\mathrm{Y}$ si en alguna Causa huviere pariedad de votos en alguna Sala passará un ministro de la otra por turno, y concurriendo éste (a quien se le hará relación) se bolverá a votar la causa, hasta dirimir la pariedad. $Y$ en los casos en que antes se estilava interponer los recursos, apelaciones o suplicaciones al Consejo de Aragón, se interpondrán y admitirán en adelante para el Consejo Real de Castilla, y si sobre esto huviere algo que necessite de reformación, lo consultatá y propondrá la Audiencia. 
Que los fiscales civil y criminal, puesto que no tendrán voto en las causas, han de poder suplicar e interponer los recursos que juzgaren convenientes y fueren permitidos de derecho sin embargo de qualquier estilo o ley que aya havido en contrario en el Reyno de Zerdeña.

\section{3 (Cataluña, 14 y 21)}

Que los quatro ministros de la Sala Criminal han de assistir en ella tres horas por la mañana todos los días que no fueren feriados para substanciar, como se ha dicho en la Sala Civil las causas, teniendo audiencia pública, martes, jueves y sábados. Y si ocurriere algún caso prompto a otras horas o en otro día, se juntarán en casa del Regente o en casa del más antiguo, si el Regente estuviere ausente o impedido. $Y$ han de assistir los dichos quatro ministros criminales a rondas, hazer fumarias, recibir informaciones y examinar testigos. $\mathrm{Y}$ cada uno de ellos podrá recibir información sobre los delitos de que tuvieren noticia y substanciar la sumaria hasta hallarse en estado de tomar la confeççión para dar quenta a la Sala, quanto esté en este estado la causa.

\section{4 (Cataluña, 16)}

Que en las causas criminales se ha de poder proceder en la Sala Criminal y demás juzgados de Zerdeña de oficio a instancia de parte o del fiscal, se ha de hazer sequestro o embargo de bienes del reo, después que sea decretada su prisión. Los términos de prueva y otros se han de poder limitar a arbitrio del juez o sala; se han de poder imponer penas pecuniarias. Y la de confiscación en los casos, y como procediere de derecho. $Y$ no a de haver lugar profano essento para las prisiones y demás que occurriere deviendo administrarse la justicia criminal sin embarazo, ni impedimento alguno, y para que esto se execute assí en todo el Reyno; y porque puede haver algunos lugares en los quales pertenesca el nombramiento de justicias a algunas Comunidades o personas particulares (sobre lo qual harán las instancias que convengan los fiscales) estará la Sala Criminal muy a la vista de todas las ciudades, villas y lugares y de sus justicias, castigará a los que de ellas fueren delinquentes o negligentes, abocará las causas que le pareciere convenir, reconociendo si están o no como deven y según lo que hallare las retendrá o debolverá $\mathrm{y}$ hará sobre esto todo quanto fuera justo y conveniente, para que en todas partes se esté con el cuydado que se deve en lo que tanto importa para la paz y quietud de aquella isla, castigo de los malos y seguridad de los buenos. Y los ministros y oficiales de justicia que nombraren las comunidades o personas particulares en los lugares y pueblos que les perteneciere antes de ponerse en exercicio deverán tener la aprobación de la Audiencia para ello, a fín de averiguar la calidad, aptitud y circunstancias que concurren en los nombramientos, y assí conviene al bien público y del estado que lo sean.

\section{5 (Cataluña, 17)}

Habrá suplicación en las causas criminales y apelación de las sentencias de los juezes ordinarios a la misma Sala Criminal. Pero si las probanzas fueren claras y 
en delitos graves conviniere no dilatar el castigo y en la Sentencia de tormento se observará lo dispuesto por derecho, pero las justicias de las ciudades, villas y lugares no podrán passar a la execución en tales casos sin consultar la sentencia y processo con la Sala a quien deverán remitir uno y otro.

16 (Cataluña, 22)

$\mathrm{Ha}$ de haver dos scribanos de Cámara para sustanciar las causas en la Sala Criminal, los quales percibirán los derechos conforme el aranzel, y seys scribanos para que assistan a los ministros criminales en las rondas y fumarias, a los quales se les señalará también sus derechos en el aranzel, y en caso de vacante, ausencia o impedimento de algunos de los dichos dos scribanos de la sala entrará uno de los seys por su turno a substanciar las causas, y si en los emolumentos o otra cosa se ofreciere alguna duda sobre esto se me consultará porque mi Real ánimo e in tención es que la justicia se administre sin retardación y con satisfación y mayor alivio de las partes.

\section{7 (Cataluña, 23)}

Que assí mismo a de haver ocho alguaziles a nombramiento mío y porque se considera que los derechos que se les señalaren en el aranzel no serán bastantes y para que puedan elegirse personas de mucha satisfación se les darán docientas libras de vellón de Zerdeña por salario fixo a cada uno.

\section{8 (Cataluña, 24)}

Que a de haver un abogado de pobres y un procurador de pobres, el abogado con salario de trescientas libras y el procurador con docientas, todas de moneda de bellón de Zerdeña al año, también a nombramiento mío.

\section{9 (Cataluña, 25)}

Que en la misma conformidad a de haver quatro porteros con doscientas libras de salario de la misma moneda cada uno para que assistan y sirvan a las Salas Civil y Criminal, assí mismo a nombramiento mío.

\section{0 (Cataluña, 26)}

Que se hayan de hazer visitas de cárceres todos los sábados por la tarde por dos ministros de la Audiencia Civil y dos de la Criminal, por turno, con assistencia del fiscal criminal y del alguazil mayor, y los martes por la tarde por toda la Sala Criminal con assistencia del fiscal, alguazil mayor. $\mathrm{Y}$ si dichos días fuessen feriados, los precedentes, y las Generales, assistiendo el Comandante General y toda la Audiencia las vísperas de Navidad, de Pasqua de Ressurrección y de Pentecostés.

\section{1 (Cataluña, 27)}

Se impondrán las penas y se estimarán las provanzas, según las leyes y práctica que avía antes en Zerdaña, y si sobre esto ocurriere alguna cosa que necessite 
de reformación, se me consultará por la Sala Criminal, se prosiguirán las causas contra reos ausentes. Y, si sobre el modo de substanciarlas y execución de las penas tuviere algún reparo la Sala, me lo consultará también.

\section{2 (Cataluña, 29)}

La Audiencia hará aranzel de los derechos de ministros subalternos y scribanos teniendo presente el antiguo de Zerdeña y le consultará conmigo, y mientras no se publique el nuevo, se observará el antiguo.

\section{3 (Cataluña, 11)}

Me dará quenta la Audiencia de los días [f]eriados que havía en la antigua de Zerdaña para establecer los que ha de haver y mientras no se resolviere observar a los de antes menos los que llamasen estivales.

\section{4 (Cataluña, 30)}

A de haver en Zerdeña corregidores con sus thenientes y regidores en las ciudades y lugares más principales y en los demás alcaldes y regidores. $Y$ en la ciudad de Caller serán los regidores veinte, y en la de Sacer doze. Y para resolver en qué ciudades y lugares ha de haver corregidor, el distrito que han de tener y el número de regidores que ha de haver, informarán el comandante general y Audiencia, con distinción del número de lugares y poblaciones assí realengos, como de señorío particular, que en cada uno de dichos distritos de corregimientos se comprehenderán; reservándome el nombramiento de corregidores y regidores en las ciudades y villas cabeças de partido o corregimiento, y en las demás villas y lugares la Audiencia nombrará de dos en dos años los alcaldes y justicias y los regidores en el número que pareciere, los quales habrán de servir un año. $\mathrm{Y}$ sobre los salarios que unos y otros habrán de tener y residencias que se han de tomar a los corregidores y alcaldes, informará también la Audiencia con relación de lo que antes se observava en Zerdeña.

\section{5 (Cataluña, 32)}

Los regidores tendrán a su cargo el govierno político de las ciudades, villas y lugares, y la administración de sus propios y rentạs con tal que no puedan hazer enagenación ni cargar censos, si no es con mi licencia o del tribunal a quien yo lo cometiere, y los que entraren de nuevo recibirán las quentas de los que acaban, con assistencia del corregidor o alcalde, el qual hará execuciones sobre alcanzes sin retardación.

\section{6 (Cataluña, 33)}

Los corregidores en los lugares de su distrito y los alcaldes en los de su jurisdición, teniendo noticia de que algunos regidores han faltado a su obligación en el oficio, harán sumaria secreta, y sin passar a prisión, ni embargo de bienes la remitirán al fiscal civil, a cuya instancia u de la parte interessada se podrá proceder contra los regidores en lo que huvieren faltado a sus oficios y los juezes serán los ministros de la Audiencia Civil, los quales podrán también proceder sobre esto de oficio. 


\section{7 (Cataluña, 34)}

No podrán los regidores juntarse sin assistencia del corregidor o su teniente o del alcalde respectivamente, como ni los gremios de artezanos o mercaderes y qualesquiera otros, los quales deverán para juntarse avisar al corregidor o alcalde para que assista o embie ministro suyo a la junta a fin que se eviten discenciones, $\mathrm{y}$ todo se trate con la quietud que es justo.

\section{8 (Cataluña, 36)}

En el cansiller de competencias y en su juzgado no se hará novedad alguna y se observará puntualmente la concordia y pragmáticas que ay sobre ello, como ni tampoco se hará novedad alguna en los recursos que en materias eclesiásticas se practican en Zerdeña.

\section{9 (Cataluña, 37 y 38)}

Todos los demás oficios que avía antes en aquel Reyno, temporales o perpetuos, $y$ todos los comunes no expressados en esta planta resuelvo y es mi voluntad que queden suprimidos y extintos; y particularmente el Tribunal de la Governación de Sacer. $Y$ que lo que a dichos oficios y comunes estava encomendado si fuere perteneciente a justicia o govierno corra en adelante a cargo de la Audiencia; y si fuere perteneciente a rentas y hazienda, quede a cargo del intendente $u$ de la persona u personas que yo deputare para esto. Pero que los oficios subalternos destinados a las ciudades, villas o lugares para su govierno político, en lo que no se opusiere a lo dispuesto en esta planta, se mantendrá. $Y$ que lo que sobre esto se necessitare de reformar me lo consultará la Audiencia o lo reformará en la conformidad que se dirá al fin respecto de ordenanzas.

\section{0 (Cataluña, 40)}

Han de sessar las prohibiciones de estrangerías porque mi Real intención es que en mis Reynos las dignidades y honores se confieran recíprocamente a mis vasallos por el mérito y no por el nacimiento en una u otra provincia de ellos.

\section{1 (Cataluña, 41)}

Las regalías de fábricas de moneda y todas las demás llamadas mayores y menores me las reservo en mí. Y si alguna comunidad o persona particular tuviesse alguna pretención en esto se le hará justicia oyendo a mis fiscales.

\section{2 (Cataluña, 42, 43 y 44)}

En todo lo demás que no está prevenido en los capítulos antecedentes desta planta, quiero y es mi voluntad, se observen las constituciones, pragmáticas y leyes que antes avía en Zerdeña, entendiéndose que son establecidas de nuevo por ésta mi Real Cédula y que tienen la misma fuerza y vigor que lo individualmente mandado en ella. Y lo mismo es mi Real voluntad se execute respecto del Consulado 
del mar que a de permanecer, y lo que fuere necessario establecer para su mejor govierno lo representará la Audiencia. Y lo mismo se observará en quanto a las ordenanzas que huviera para el govierno político de las ciudades, villas y lugares en lo que no fuere contrario a lo mandado aquí con tal que sobre las referidas ordenanzas, respecto de las ciudades y lugares cabezas de partido o corregimiento, se me consulte por la Audiencia lo que considerare digno de reformar, y en los demás lo reformará la Audiencia. Por tanto os mando que luego que recibays esta mi Zédula la veáys, guardéys, cumpláys y executéys y hagáys guardar, cumplir y executar en todo y por todo según y como en ella se expressa y contiene sin la contravenir ni permitir que se contravenga en manera alguna con ningún pretexto ni motivo, y me consultaréys promptamente en los casos y cosas que se exceptúan y previenen en los referidos capítulos, para que enteramente quede arreglado el govierno político y económico de esse Reyno dando a este fin y para el más exacto cumplimiento de lo que va expressado todas las órdenes y providencias que os pareciere convenientes y assí mismo haréys poner esta mi Real Zédula en el archivo de essa Audiencia para su mayor estabilidad y observancia y que de ella se saquen los traslados que fueren necessarios para que se consiga y tenga cumplido efecto ésta mi resolución a los quales estando autorizados y legalizados en forma quiero se las dé entera fee y crédito como si fuesse a esta mi Zédula original, que assí es mi voluntad. Dada en Madrid a diez y seys días del mes de Febrero, año de mil setecientos y diez y nueve. Yo el Rey. Yo Don Iuan Milán de Aragón, Secretario del Rey nuestro Señor, lo hize escrivir por su mandado. Registrada. Salvador Narváez. Theniente de Canciller mayor: Don Salvador Narváez. Lugar del Sello. Don Luis de Miraval. Don Andrés de Medrano. Don Gregorio de Mercado. Don Francisco de Ameller. V. Magestad manda al Comandante General y al tegente y oydores de la Audiencia del Reyno de Cerdeña guarden y observen lo resuelto en los treinta y dos Capítulos aquí insertos sobre la formación de la Audiencia y Govierno de dicho Reyno. Scribano de Cámara Don Ioseph Bordonaba. 